\section{UK scientists keep access to the Gemini telescopes}

Britain has reached an agreement that will allow UK astronomers continued access to the Gemini Observatory.

In November, the UK Science and Technology Facilities Council (STFC) announced its intention to withdraw from the observatory - which has 8-metre telescopes in Mauna Kea in Hawaii and Cerro Pachon in Chile - because of a budget shortfall (see Nature 450, 468; 2007). Subsequent negotiations to retain access to the Hawaiian telescope failed, raising fears that British astronomers would have no access to a large telescope in the Northern Hemisphere.

But on 27 February the STFC announced that it would remain in the Gemini partnership. It plans to save money by selling a portion of its nearly $\mathfrak{£ 4}$ million (US\$7.9 million) annual subscription for telescope time to other interested nations.

"I welcome this announcement," says Michael Rowan-Robinson, president of the Royal Astronomical Society. Dropping out, he says, would have been "very bad for the United Kingdom's reputation as an international partner".

\section{Massachusetts gears up to boost cash for life sciences}

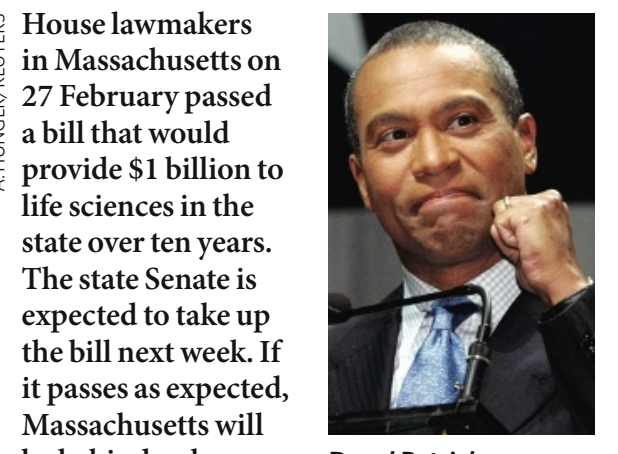
be behind only Deval Patrick.

\title{
Lunar pole is revealed in high resolution
}

\section{NASA has released} radar pictures of the Moon's south polar region - the best ever, with a resolution of 40 metres, showing up the steep slopes and rugged topography (see right).

Taken using the

Goldstone Solar

System Radar facility in California's Mojave Desert, the pictures could help NASA to

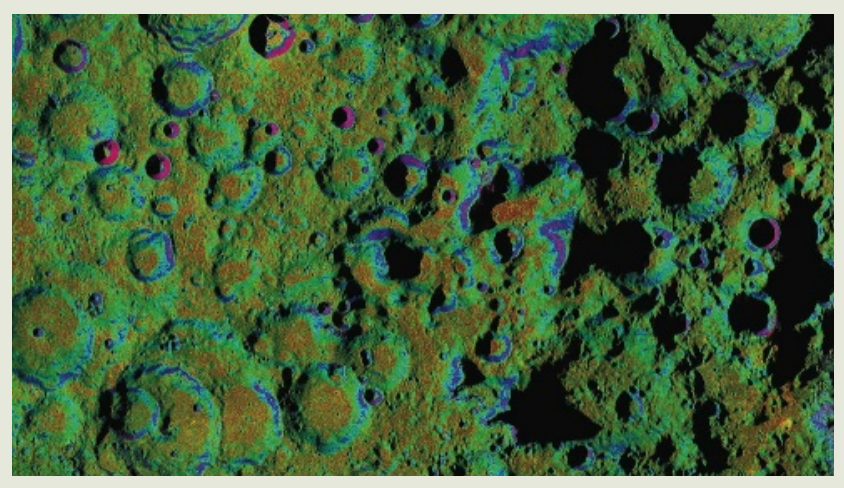

find smooth, flat landing areas for future rovers, or suitable spots for a lunar base. The south polar region is of particular interest because some areas, particularly those deep inside craters, are in perpetual shadow and may contain permanently frozen water that could be used as a resource.

But the Goldstone pictures, released on 27 February, do nothing to resolve the debate about whether there is water ice buried beneath the surface because the radar wavelengths used (3 centimetres) do not penetrate the surface well and an analysis of the polarization of the returning signal wasn't performed. Scientists hope that the Lunar Reconnaissance Orbiter, scheduled to launch later this year, will settle the ice question.

\section{First of three contested stem-cell patents upheld}

In a dispute over three stem-cell patents, Wisconsin Alumni Research Foundation (WARF) is claiming victory, after an interim decision from the US Patent and Trademark Office to uphold one of its patents.

On 28 February, WARF said that the claims of a 2001 patent on a method for growing and sustaining cultures of embryonic stem cells had been upheld. The patent is one of three on work led by James Thomson of the University of Wisconsin. The other two cover methods for deriving primate embryonic stem cells - including human ones - and the cells themselves.

In 2006, after critics challenged the patents on the basis that they were too broad and hindered the field of embryonic stem-cell research, the patent office said it would re-examine the three. The critics played down last week's decision, saying that WARF has already limited its claims in the upheld patent, and that the other two patents are more important. Rulings on those are still pending.

\section{India to propose regulatory body to curb misconduct}

India is to consider creating a national body to investigate plagiarism and misconduct in science after a string of high-profile frauds.

C. N. R. Rao, who heads the national science advisory committee, told Nature that he will discuss the proposal at his next meeting with Prime Minister Manmohan Singh. Rao was reacting to the news that Sri Venkateswara University in southern India is to reopen a massive fraud case involving chemistry professor, Pattium Chiranjeevi. Last month, Chiranjeevi was found guilty of plagiarizing or falsifying more than 70 research papers published in a variety of Western scientific journals between 2004 and 2007. Some of the journals have started retracting the articles.

\section{US\$50 billion agreed for Bush's global AIDS plan}

Lawmakers in the US House of Representatives reached a key compromise last week clearing the way for a vote that could more than triple US funding to fight AIDS, malaria and tuberculosis.

The bill renews the President's Emergency Plan for AIDS Relief, a \$15-billion, five-year law created by President Bush in 2003. Its new incarnation would provide $\$ 50$ billion over the next five years, with $\$ 9$ billion of that earmarked for fighting tuberculosis and malaria, which often affect patients with AIDS. Crucially, it does not require, as did its predecessor, that one-third of HIV/AIDS prevention money be spent on advocating abstinence. Instead, it asks countries to justify to Congress any decision to spend less than $50 \%$ of prevention dollars on promoting abstinence and faithfulness.

The Senate Foreign Relations Committee is working on its own version of the bill aiming for a similar compromise on the abstinence language.

\section{Correction}

The Editorial 'Time to take control' (Nature 451, $1030 ; 2008$ ) failed to make it clear that Mark Grabowsky's assertion that "the billion-dollar malaria effort is flying blind" relates specifically to a lack of disease surveillance. Apologies.
Governor Deval Patrick introduced the measure last spring. 